\title{
ANÁLISIS DEL MODELO DE INDUSTRIALIZACIÓN POR SUSTITUCIÓN DE IMPORTACIONES EN AMÉRICA LATINA Y EN ARGENTINA. UNA MIRADA HACIA LA REALIDAD INDUSTRIAL ACTUAL EN ARGENTINA
}

\section{ANALYSIS MODEL IMPORT SUBSTITUTION INDUSTRIALIZATION IN LATIN AMERICA AND ARGENTINA. A LOOK INTO THE CURRENT INDUSTRIAL REALITY IN ARGENTINA}

\author{
Mgter. Prof. Fernando Ariel Bonfanti \\ Prof. Auxiliar cátedra Geografía Económica y Política General \\ Departamento de Geografía-Facultad de Humanidades-UNNE
}

\section{RESUMEN}

El modelo de Industrialización por Sustitución de Importaciones, ha sido un modelo de desarrollo que se propuso el reemplazo de bienes importados por bienes producidos localmente. Las políticas económicas derivadas de este modelo fueron aplicadas principalmente durante las décadas del ' 50 y ' 60 en los países de América Latina.

Algunos economistas resaltan que la aplicación de este modelo llevó a un aumento del empleo, al surgimiento de sectores industriales nacionales, al ahorro de divisas y por sobre todo a la disminución de la influencia y dependencia del extranjero, mientras otros afirman que el modelo condujo a elevados precios de bienes manufacturados, ineficiente asignación de recursos, pérdida de oportunidades de exportaciones y endeudamiento externo.

Particularmente en Argentina, la crisis del año 2001 impactó en forma negativa y muy fuertemente en el sector industrial, el desempleo se elevó considerablemente, producto de la desindustrialización y las empresas siguieron quebrando, a causa de la economía debilitada. Recién en el período 2003-2007 la industria argentina creció en forma persistente acompañando la dinámica de la economía en su conjunto, destacándose sector manufacturero.

Palabras claves: Economía; Importaciones; Industrialización; Argentina

\section{ABSTRACT}

The model of import substitution industrialization, has been a model of development that the replacement of imported goods for goods produced locally is proposed. Economic policies derived from this model were applied mainly during the decades of the $50 \mathrm{~s}$ and $60 \mathrm{~s}$ in Latin America.

Some economists point out that the application of this model led to an increase in employment, the rise of national industries, saving foreign exchange and above all to the decline in the influence and dependence on foreign, while others claim that the model led to high prices of manufactured goods, misallocation of resources, loss of export opportunities and foreign debt.

Particularly in Argentina, the crisis of 2001 negatively impacted very strongly in the industrial sector, unemployment rose sharply, due to deindustrialization and companies continued breaking, because of the weakened economy. Just in 2003-2007 the Argentina industry grew persistently accompany the dynamics of the economy as a whole, highlighting manufacturing.

Keywords: Economy; Imports; Industrialization; Argentina

Publicado en formato digital: Mgter. Prof. Fernando Ariel Bonfanti. ANÁLISIS DEL MODELO DE INDUSTRIALIZACIÓN POR SUSTITUCIÓN DE IMPORTACIONES EN AMÉRICA LATINA Y EN ARGENTINA. UNA MIRADA HACIA LA REALIDAD INDUSTRIAL ACTUAL EN ARGENTINA. Revista Geográfica Digital. IGUNNE. Facultad de Humanidades. UNNE. Año 12. No 24. Julio - Diciembre 2015. ISSN 1668-5180 Resistencia, Chaco.

En: http://hum.unne.edu.ar/revistas/geoweb/default.htm 


\section{Introducción}

En el presente artículo se hace referencia a los principales rasgos que caracterizaron el proceso de Industrialización por Sustitución de Importaciones, su surgimiento y consolidación en Argentina y América Latina y su posterior declinación. Asimismo, se describen algunas particularidades que formaron parte del desarrollo industrial argentino durante estos últimos años.

Podríamos comenzar diciendo que la Industrialización por Sustitución de Importaciones (ISI) se basó principalmente en el crecimiento del sector industrial desde adentro y ha estado vigente durante el período que va desde principios de la década de 1930 hasta finalizar la década del ` 70 . Es decir que, durante más de cuarenta años, la ISI prevaleció bajo distintos gobiernos y circunstancias históricas, impulsado por el sector industrial, principal motor del crecimiento productivo, no solo de los argentinos sino también de muchos países latinoamericanos. Precisamente, fue este sector el que experimentó una gran expansión debido, entre otras cosas, a la mayor capacidad adquisitiva de la población y al proteccionismo aduanero, medida que evitaba la entrada al país -y por lo tanto la competencia- de los bienes manufacturados importados, similares a los que se producían en los propios países.

\section{El origen del modelo:}

Podemos ubicar la puesta en marcha de este modelo de desarrollo, orientado a satisfacer la demanda interna gracias a la estimulación de la capacidad de compra de los consumidores nacionales, en el momento en que se produce la crisis internacional ocurrida luego de la Gran Depresión de 1929. Dicha crisis también tuvo su impacto en nuestro territorio, ya que los precios de los productos que exportábamos (trigo, maíz y carne) manifestaron una abrupta caída como consecuencia de la disminución de la demanda mundial de esos productos a causa de la recesión existente. Debido a ello, los sectores de mayor poder en la Argentina (ganaderos y empresarios) resolvieron cambiar el rumbo de la economía nacional. Fueron ellos quienes decidieron sustituir el modelo agroexportador, de gran éxito entre 1850 y 1929, por otro modelo que pudiera enfrentar la aguda contracción de la producción y el empleo.

Como las actividades agropecuarias destinadas a la exportación ya no aseguraban la rentabilidad suficiente, estos sectores comenzaron a incentivar la industrialización a través de la adopción de medidas que buscaban la protección de lo local respecto a los productos de importación, surgiendo en ese contexto las medidas proteccionistas del Estado.

Es decir que la ISI surgió en un contexto histórico propicio, donde el orden liberal mundial había colapsado, donde la ola globalizadora de finales del siglo XIX, así como la gran crisis que desemboca en la depresión de los años treinta facilitaron su implementación y un viraje en el pensamiento del desarrollo hacia adentro, de ahí que Gerald consideró que ésta no fue forzada por el pensamiento de la CEPAL sino que fue una alternativa objetiva resultante de la situación internacional (Gerald, 1998).

Aunque realmente estos factores son considerados circunstanciales (Vidal, 2007) y el verdadero origen del modelo descansa en los limites objetivos del modelo anterior primario exportador y en la posición que ocupaban los países latinoamericanos en la división internacional del trabajo, el desequilibrio externo que conducía a crisis recurrentes, con importantes recesiones, procesos inflacionarios, obedecía al deterioro de los términos de intercambio entre los productos primarios exportados por la periferia y los manufacturados por los países centrales, lo que obligaba a impulsar una industrialización mediante una estrategia en donde la acción económica del Estado juegue un papel central además de aprovechar la cobertura internacional de la depresión y la guerra.

Entre los principales objetivos del modelo se trataba de asignar a los agentes internos, un papel más decisivo en la creación de una base endógena que fuera capaz de promover el crecimiento de la economía y la industrialización dejando que las fuerzas externas solo ocupen un papel complementario. El modelo también pretendía elevar el nivel de empleo y que la distribución del ingreso sea igualitaria para así poder incrementar la demanda solvente de los consumidores y reducir la heterogeneidad estructural.

Publicado en formato digital: Mgter. Prof. Fernando Ariel Bonfanti. ANÁLISIS DEL MODELO DE INDUSTRIALIZACIÓN POR SUSTITUCIÓN DE IMPORTACIONES EN AMÉRICA LATINA Y EN ARGENTINA. UNA MIRADA HACIA LA REALIDAD INDUSTRIAL ACTUAL EN ARGENTINA. Revista Geográfica Digital. IGUNNE. Facultad de Humanidades. UNNE. Año 12. No 24. Julio - Diciembre 2015. ISSN 1668-5180 Resistencia, Chaco.

En: http://hum.unne.edu.ar/revistas/geoweb/default.htm 
Este modelo no se desarrolló a un mismo ritmo en toda América Latina, los primeros países en experimentar el proceso fueron aquellos que tenían los centros urbanos más grandes y contaban con una clase media fuerte, es decir Brasil en primer lugar, luego Argentina, Chile y México, según puede observarse en el mapa siguiente.

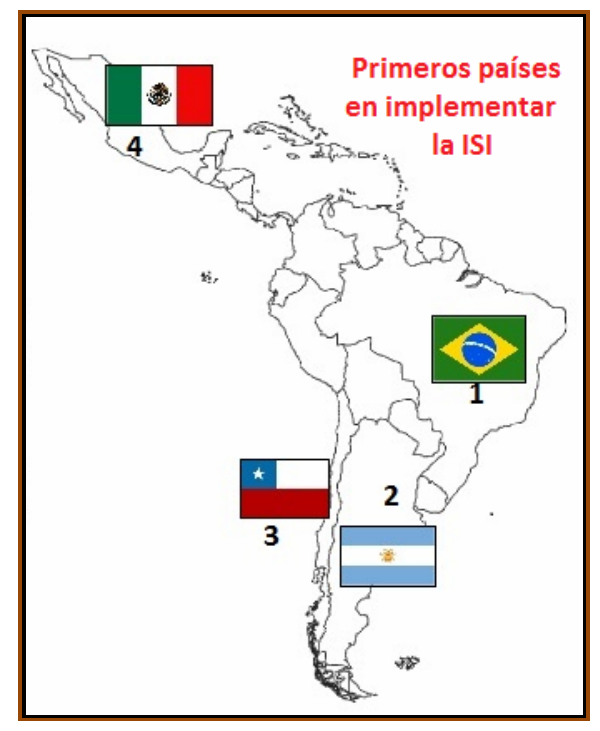

Fuente: Elaboración propia

El modelo ISI atravesó varias etapas con características propias para Latinoamérica en su conjunto (González Arévalo, 2009)

Según la autora, una primera etapa donde se logró realmente sustituir las importaciones de manufactura por fabricación interna. En un principio donde primaron las fuertes restricciones a las importaciones la sustitución se apoyó en la demanda existente. Las devaluaciones del tipo de cambio de las monedas y las políticas defensivas de ingreso adoptadas por los gobiernos por las crisis facilitaron el proceso sustitutivo.

En el caso particular de la Argentina hubo que apelar a los excedentes generados por el sector agropecuario para poder generar capacidad de importar.

Pero debido a la convergencia de factores internos y externos, las exportaciones agropecuarias entraron en un prolongado periodo de estancamiento. En consecuencia, las fases de expansión de la actividad industrial y, consecuentemente, de aumento de su déficit de divisas, tropezaban con un "cuello de botella" en el balance de pagos, es decir, la "restricción externa". Una vez que se agotaban las posibilidades de endeudamiento, el epílogo era el ajuste para restablecer el equilibrio perdido. En semejante escenario, las finanzas públicas incurrieron repetidamente en déficit. La restricción institucional, provocó políticas erráticas que agravaron las otras dos: la externa y la fiscal. La consecuencia más evidente de estos hechos fue el desorden monetario y la inflación crónica y elevada, que se instala a partir de 1945 (Ferrer, 2010).

La segunda etapa, comprendida por dos décadas que van desde los primeros años de los '50 hasta inicio de los '70, se la considera como la edad de oro de este modelo. No obstante en el decenio de 1960 la evolución industrial empieza a dar muestras de debilitamiento, cuya manifestación fue la elevada protección que amparó el crecimiento de este sector secundario. La política de industrializar consistía en fomentar la inversión privada pero a la vez reducida lográndose así la importación de bienes de capital. Se pretendía dar estímulos a la producción de bienes de consumo no duradero en primer lugar y, posteriormente, los duraderos e intermedios, sacrificándose el desarrollo local de la maquinaria y equipo (González Arévalo, 2009).

Publicado en formato digital: Mgter. Prof. Fernando Ariel Bonfanti. ANÁLISIS DEL MODELO DE INDUSTRIALIZACIÓN POR SUSTITUCIÓN DE IMPORTACIONES EN AMÉRICA LATINA Y EN ARGENTINA. UNA MIRADA HACIA LA REALIDAD INDUSTRIAL ACTUAL EN ARGENTINA. Revista Geográfica Digital. IGUNNE. Facultad de Humanidades. UNNE. Año 12. No 24. Julio - Diciembre 2015. ISSN 1668-5180 Resistencia, Chaco.

En: http://hum.unne.edu.ar/revistas/geoweb/default.htm 
En esta etapa, en palabras de Guillén, las ETN (Empresas Transnacionales) capitalizaron el desarrollo del mercado interno y se apoderaron de las ramas y actividades más dinámicas de la industria. Esto implicó el traslado hacia el exterior de las tomas de decisiones, generando un debilitamiento en la conducción nacional del proceso y limitando el campo de acción y la influencia de las políticas económicas de los gobiernos. Este autor afirma que "las decisiones fundamentales para la continuación del proceso de industrialización dejaron de estar en manos nacionales y pasaron a depender de decisiones externas, altamente centralizadas tomadas en el ámbito de las ETN" (Guillén, 2008). En este período las importaciones de bienes finales también fueron sustituidas por compra de bienes intermedios y de capital, lo cual generó un desequilibrio comercial que aumentó más rápido que el $\mathrm{PBI}$, provocando que las soluciones se busquen en los empréstitos que devinieron en la consecuente abultada deuda externa.

Finalmente, la tercera etapa de esta política de ISI se ubica a finales de los años '70, y se caracterizó porque los objetivos de las etapas anteriores a ella no habían sido cumplidos. Este proceso económico llevado a cabo empezó a agotarse por fallas estructurales, la industria no permitió impulsar la elaboración de artículos de consumo que se tradujera en crecientes exportaciones, ni alcanzó a producir bienes de capital con niveles que tuvieran la posibilidad de hacer descender el stock de importaciones, acentuándose el problema de la balanza de pagos y muchos países tuvieron que recurrir constantemente al endeudamiento con el exterior (González Arévalo, 2009).

Al analizar el modelo ISI en América latina, existen países como Nicaragua u Honduras donde su aplicación fue muy débil, en tanto que los países de mayor desarrollo relativo -en general- como Brasil, Argentina y Chile además de México en Centroamérica brindan una idea más general de la implementación del modelo en el continente (Hirschman, 1996). En lo que se refiere a Argentina y Chile, el mismo Hirschman señala la ocurrencia de una industrialización en conjunto a la desindustrialización, producto del efecto adverso de las políticas monetarias aplicadas sobre todo después de 1978, la más importante fue la sobrevaluación de la moneda nacional considerada como un instrumento antinflacionario, la medida no resultó muy eficaz para tal propósito, pero otorgó una ventaja de costo artificial a un gran conjunto de mercancías. Entre las industrias fuertemente afectadas, no sólo estaban la manufactura de bienes y consumos tradicionales, tales como la de textiles y calzado, sino ciertos bienes de consumo duraderos de tecnología avanzada.

En términos de Aldo Ferrer (2010), la dictadura argentina aplicó una política de liberación de las importaciones y desregulación financiera con una fuerte revaluación del tipo de cambio. En un contexto de globalización de las relaciones financieras internacionales la deuda externa creció vertiginosamente, pues pasó de 3 mil millones en 1975 a cerca de 50 mil millones de dólares en 1983. América Latina fue la región del mundo que más se endeudó en aquellos años y la Argentina el país que batió el récord. El período constituye la segunda renuncia a una estrategia de industrialización y desarrollo integrado de la economía argentina, acorde a lo afirmado anteriormente por Hirschman (1996); la primera se había registrado cuando la postura librecambista se impuso a la estrategia industrialista de López y Pellegrini. Pero además, existe una gran diferencia entre ambas experiencias: en la del siglo XIX, se ofrecía un rumbo alternativo de desarrollo fundado en la plena inserción de la economía argentina en el mercado mundial. En éste, los productos primarios constituían 2/3 del comercio internacional. La renuncia de 1976, en cambio, fue un salto al vacío y una opción inviable porque el desarrollo de largo plazo es imposible con el desmantelamiento de la industria y crecientes endeudamientos y vulnerabilidad externa (Ferrer, 2010). Asimismo, el mismo Aldo Ferrer (2012:100) sostuvo que "la desindustrialización fracturó cadenas de valor, afectó particularmente a las pequeñas y medianas empresas, aumentó el desempleo y agravó la desigualdad en la distribución del ingreso".

En toda América Latina la década de 1980 arrojó resultados negativos pero en la Argentina fueron peores que en el conjunto de la región. En ese período, el producto per cápita latinoamericano cayó $9 \%$ y en Argentina $21 \%$.

En el caso de México, lo peculiar fue la gran ola de importaciones en que incurrió al país. Hacia fines de la década del '60 se han descubierto importantes yacimientos de petróleo, lo cual convirtió al territorio en un gran productor y exportador de dicho recurso. La acumulación considerable de divisas abrió las puertas del consumo, aumentando considerablemente el coeficiente importador,

Publicado en formato digital: Mgter. Prof. Fernando Ariel Bonfanti. ANÁLISIS DEL MODELO DE INDUSTRIALIZACIÓN POR SUSTITUCIÓN DE IMPORTACIONES EN AMÉRICA LATINA Y EN ARGENTINA. UNA MIRADA HACIA LA REALIDAD INDUSTRIAL ACTUAL EN ARGENTINA. Revista Geográfica Digital. IGUNNE. Facultad de Humanidades. UNNE. Año 12. № 24. Julio - Diciembre 2015. ISSN 1668-5180 Resistencia, Chaco.

En: http://hum.unne.edu.ar/revistas/geoweb/default.htm 
hasta llegar incluso a superar las exportaciones. El aumento de los precios internos unido a la negativa del gobierno de devaluar o restringir las importaciones, rápidamente generó una sobrevaluación de la moneda, produciendo así la fuga masiva de capitales. La riqueza petrolera le sirvió a México como garante para los préstamos bancarios internacionales necesarios ante la situación descrita, lo cual posteriormente trajo como resultado una intensa crisis en la demanda, devaluaciones de todo tipo y recesión de la economía mexicana.

Brasil fue el único país que logró impulsar la política de industrialización. A pesar de que era el mayor deudor de América Latina, utilizó los préstamos y la inversión extranjera directa para fomentar los proyectos industriales. El país desvió las inversiones industriales de automóviles y de bienes de consumo duradero hacia los insumos intermedios, sobre todo las industrias químicometalúrgicas y los bienes de capital. Aunque esto no fue suficiente para lograr aumentar el tamaño del mercado, erradicar la alta concentración del ingreso o la restricción de divisas.

Analizando el modelo desde una óptica generalizadora encontramos que desde 1950 hasta 1980, América Latina creció a una tasa media anual de casi 5,5 \% (Sonntag, 1994). La sustitución de importaciones logró impulsar la industria pesada en algunos de los países más grandes de la región y creó una modesta base para el crecimiento de la industria manufacturera interna.

A inicios del modelo, en los años 40 en América Latina existían sociedades generalmente agrarias o mineras con economías monoproductoras, con pequeños e incipientes rasgos de industrialización. En el curso del modelo a finales de los '60, los sectores primarios estaban más desarrollados y eran menos dependientes de un solo producto, los sectores industriales habían crecido, se hallaban más diversificados y contaban con sectores terciarios ampliados. En cuanto a la inserción en el sistema mundial, ésta era menos desfavorable, había aumentado su participación en el comercio mundial en un 12 \%, debido a la diversificación y modernización del sector primario (Sonntag, 1994:271).

En el aspecto social se habían experimentados cambios profundos. La educación se había masificado, tanto en los niveles secundario como universitario, en el plano de la salud las políticas sociales aplicadas han generado una reducción de la mortalidad infantil, el aumento de la esperanza de vida, la disminución de las enfermedades endémicas y otros. Para redondear un gran número de avances dentro de la estrategia de sustitución, también se han logrado avances importantes en materia de servicios públicos como agua potable, sistemas de comunicación, etc. así como en aspectos socioculturales.

\section{La declinación del modelo}

Aunque es evidente que la ISI constituyó un paso de avance en un proceso de desarrollo autóctono y nacional cimentando sus bases en el fortalecimiento del mercado interno, modificando las estructuras productivas en parámetros más modernos y estableciendo mejoras en los problemas de la inequidad en la distribución del ingreso y en políticas sociales dirigidas hacia la educación y la salud, el proceso fue considerado un fracaso como modelo de desarrollo, En si, esto no debería haber causado sorpresa si se tomaba en cuenta que desde un principio éste se vio envuelto en una gran vulnerabilidad frente al exterior debido a la sobrevaluación cambiaria que acompaño a este proceso, la cual desestimuló las exportaciones y aumentó la dependencia de importaciones de bienes intermedios y de capital (Lustig, 2000).

La sustitución de importaciones y la industrialización no generaron, en medida suficiente, ventajas competitivas para acceder a los renglones más dinámicos del mercado mundial, esto es, los vinculados con las manufacturas de mayor contenido tecnológico (Fajnzylber, 1983). En otras palabras, la región no logró aumentar la productividad en la industria con respecto a la media internacional, y por lo tanto, eran muy raras las posibilidades de que la economía pudiera insertar nuevos productos dentro de sus líneas de exportación. El objetivo final de la estrategia de la ISI, que era cambiar el patrón de inserción de la región en el mercado mundial, no se había alcanzado. En este sentido, cabe aclarar también que, los ciclos de crecimiento sufrieron alteraciones en forma periódica debido al estrangulamiento externo y a la necesidad del ajuste.

Publicado en formato digital: Mgter. Prof. Fernando Ariel Bonfanti. ANÁLISIS DEL MODELO DE INDUSTRIALIZACIÓN POR SUSTITUCIÓN DE IMPORTACIONES EN AMÉRICA LATINA Y EN ARGENTINA. UNA MIRADA HACIA LA REALIDAD INDUSTRIAL ACTUAL EN ARGENTINA. Revista Geográfica Digital. IGUNNE. Facultad de Humanidades. UNNE. Año 12. No 24. Julio - Diciembre 2015. ISSN 1668-5180 Resistencia, Chaco.

En: http://hum.unne.edu.ar/revistas/geoweb/default.htm 
El predominio de algunas filiales de empresas internacionales en las áreas industriales más complejas debilitó la capacidad de integrar la producción de bienes y servicios con los sistemas nacionales de ciencia y tecnología y con la oferta interna de insumos complejos. A consecuencia de ello, no se desarrolló suficientemente la capacidad endógena de asimilación y transformación de las tecnologías importadas ni de innovación original.

La vulnerabilidad externa se agravó por una tendencia generalizada de desequilibrio fiscal y creciente endeudamiento público. Estas tendencias reflejaban la baja capacidad de arbitraje del Estado en las pujas distributivas del ingreso, inherentes a la inestabilidad institucional que prevalecía en ese entonces. La política monetaria no resistió la agresión simultánea desde el frente externo y del deterioro fiscal y, de manera generalizada, ratificó las presiones inflacionarias. La inflación se instaló entonces como un mal endémico durante la fase del crecimiento hacia adentro.

Otra deficiencia marcada la representó la heterogeneidad estructural, problema que se originó debido a la poca capacidad de absorción de mano de obra en el sector moderno industrial proveniente de sectores rurales fundamentalmente o comunidades aborígenes.

A pesar del dinamismo de la industria, cuando ésta operaba con técnicas de producción intensivas en capital importadas del centro, resultó incapaz de absorber la migración procedente del campo, dando origen al fenómeno de la economía informal, que ahora nos inunda (Guillén, 2008).

Un segundo elemento refiere al mecanicismo de la teoría. En donde predominaba el economicismo y en consecuencia la creencia de que la modernización del sistema productivo iba a implicar una mayor movilidad social. Con respecto a ello, se puede decir que un causa importante del fracaso del modelo fue la incapacidad de generar una clase media que ayudara a consolidar las industrias nacientes a semejanza de lo ocurrido en las sociedades occidentales durante el desarrollo de sus procesos de industrialización. Tal y como muestran algunos autores, "el éxito en la sustitución de importaciones en los países con una distribución de rentas muy desigual -como es el caso latinoamericano- está ligado básicamente a los grupos de ingresos medios" (Grunwald, 1964:304).

Otro elemento que condujo al fracaso fue el uso sobredimensionado del arancel, que no fue utilizado como herramienta de promoción de largo plazo sino como instrumento de recaudación fiscal. En este sentido, la protección arancelaria exterior fue durante este período muy elevada, ya que se perseguía una verdadera sustitución de las importaciones, lo que introdujo importantes ineficiencias en la asignación de los recursos a escala nacional como consecuencia de la fijación de unos precios y costes relativos interiores que no respondían a la realidad de las condiciones competitivas de la economía regional (Muns, 1972).

Un cuarto elemento refiere al fracaso de los propios postulados. En sí, la industrialización sustitutiva no llegó a cumplir, prácticamente en ninguna sociedad las tres fases previstas en la estrategia, sustitución de bienes de consumo, intermedio y capital, pues resultó imposible que cada una de ellas engendrara en lo fundamental las condiciones para el inicio de la próxima.

Por último, se puso de manifiesto una cierta ingenuidad por parte del proceso en cuanto a la percepción del modo del funcionamiento del sistema mundial, al no interpretar el papel real que juegan los países del primer mundo en su aporte al desarrollo de los más atrasados.

Así las cosas, durante la década del '80 (en que comienza a hacerse notar el fenómeno de la globalización), los países tuvieron la necesidad de abandonar este modelo para abrirse a los mercados internacionales. Para insertarse "correctamente" a este nuevo proceso globalizador, las economías tuvieron que abandonar el programa de subsidios para promover las exportaciones, con el objeto de acercarse a las condiciones de competencia internacionales. De igual manera se establecieron aranceles que de apoco reemplazarían a las cuotas implementadas, y más adelante poco a poco irían rebajándolos hasta hacerlos desaparecer (Ferrer, 2010).

Finalizada entonces la etapa ISI, se da inicio a un período en el que comienzan a utilizarse nuevas estrategias relacionadas con el dinamismo económico. La principal fue la de la privatización de empresas y reducción de la pobreza. Por otro lado, se buscaba atraer la inversión extranjera directa, generando de este modo la posibilidad de proveer a los países de los recursos que eran escasos debido a que no se había tenido movilidad de divisas con el modelo anterior.

Esta metodología de apertura de las fronteras era tanto necesaria como inevitable debido al momento histórico y a sus demandas, pero en cierto modo fue contraproducente para las economías,

Publicado en formato digital: Mgter. Prof. Fernando Ariel Bonfanti. ANÁLISIS DEL MODELO DE INDUSTRIALIZACIÓN POR SUSTITUCIÓN DE IMPORTACIONES EN AMÉRICA LATINA Y EN ARGENTINA. UNA MIRADA HACIA LA REALIDAD INDUSTRIAL ACTUAL EN ARGENTINA. Revista Geográfica Digital. IGUNNE. Facultad de Humanidades. UNNE. Año 12. No 24. Julio - Diciembre 2015. ISSN 1668-5180 Resistencia, Chaco.

En: http://hum.unne.edu.ar/revistas/geoweb/default.htm 
ya que debido a que la industria nacional no alcanzó a desarrollarse correctamente durante el período ISI, al abrirse al comercio internacional, los productos provenientes de otros países resultaron ser mejores que los que se producían en los mercados internos, lo cual provocó que se dispararan las importaciones, ocasionando un déficit comercial. Para financiarlo se necesitaba la inversión extranjera, lo cual hacía a las economías vulnerables a los shocks externos. Este proceso que se fue dando en muchos países y provocó el debilitamiento de las economías, lo que más tarde desembocaría en las crisis que ya conocemos como efecto Tequila -México 1995- y la Argentina durante el 2001 (Ferrer, 2010).

\section{El período final del proceso ISI en Argentina y la etapa siguiente}

En los párrafos anteriores ya se afirmó que este proceso, iniciado en América Latina luego de la crisis mundial de 1930, llegó a su fin a principios de la década del '80, siendo ésta región la que más endeudamiento tenía por aquellos años y Argentina el país que batió el récord, sobre todo por las malas políticas económicas desarrolladas durante el gobierno militar.

A partir de 1983, con el retorno de la democracia y durante el gobierno de Raúl Alfonsín, las cuestiones comenzaron a cambiar, pero así y todo nuestro país no logró librarse de la deuda y de las restricciones externa y fiscal. A principios de los '90, el gobierno de Carlos Menem se aferró incondicionalmente al paradigma neoliberal, con más profundidad que en cualquier otro país de América Latina y el resto del mundo. Con la aplicación del régimen de convertibilidad se produjo la dolarización del sistema monetario y se renunció a toda forma posible de tener una política económica nacional; de este modo, la marcha de la economía quedaba sujeta al movimiento de capitales especulativos. Al mismo tiempo, la venta de los principales activos públicos (llámese privatizaciones), transfirió a manos privadas los servicios energéticos, el transporte, las telecomunicaciones, el petróleo y otros activos principales, a filiales de empresas multinacionales.

Los ingresos generados por dichas privatizaciones, más el reinicio de la corriente de capitales especulativos generaron un incremento inicial de la economía, ya que se vivía un período en el que el tipo de cambio fijo permitió estabilizar el nivel general de precios (teniendo en cuenta que años anteriores se sufrieron los efectos de la hiperinflación). Pero aun así, la restricción externa se multiplicaba debido a tres factores: al valor que tenía el peso argentino (un peso = un dólar), a la pérdida de competitividad de la producción nacional y al aumento de la deuda externa.

Según conceptos vertidos por Vaccarezza, la política industrial en la década del '90 ha desarrollado algunos mecanismos para impulsar la inversión mediante subsidios a la adquisición de plantas llave en mano y bajas de aranceles a la importación, como también algunos aislados esquemas de promoción regional, y la creación de la SEPYME (Subsecretaria de la Pequeña y Mediana Industria creada a mediados de los años noventa dentro de la órbita del Ministerio de Economía y con una serie de programas regulados por ley a fin de estimular el desarrollo del sector de PYMES industriales en la argentina, que sin duda fue el menos beneficiado de los sectores por el esquema de incentivos del modelo económico) que tuvo una trayectoria fallida, pobre y errática; y recién en el año 2004 pudo poner en marcha el conjunto de todos sus programas.

Así y todo, las restricciones tanto externa como fiscal bajo el período de la ISI, no impidieron un crecimiento considerable de la economía argentina y una mejora de las condiciones sociales. En cambio, bajo el paradigma neoliberal, el periodo 1976-2001/02, fue el peor de la historia económica argentina (Ferrer, 2010).

\section{La etapa industrial actual}

A partir del año 2003, bajo el gobierno de Néstor Kirchner, se manifiesta un nuevo escenario industrial para la Argentina, con grandes cambios y crecimiento para el sector. A pesar de que la producción nacional comenzó a crecer desde ese año, dando lugar a un incremento en las exportaciones, también es cierto que las importaciones igualmente aumentaron, y según el INDEC lo

Publicado en formato digital: Mgter. Prof. Fernando Ariel Bonfanti. ANÁLISIS DEL MODELO DE INDUSTRIALIZACIÓN POR SUSTITUCIÓN DE IMPORTACIONES EN AMÉRICA LATINA Y EN ARGENTINA. UNA MIRADA HACIA LA REALIDAD INDUSTRIAL ACTUAL EN ARGENTINA. Revista Geográfica Digital. IGUNNE. Facultad de Humanidades. UNNE. Año 12. No 24. Julio - Diciembre 2015. ISSN 1668-5180 Resistencia, Chaco.

En: http://hum.unne.edu.ar/revistas/geoweb/default.htm 
han hecho a un ritmo más elevado desde 2003. Por lo tanto, no se puede hablar de un proceso de industrialización por sustitución de importaciones, concepto fundamental para el desarrollo industrial.

En este sentido, Azpiazu y Schorr (2010:138) muestran que el crecimiento de las exportaciones industriales, notable durante el período, es producto de la cúpula industrial, mientras que el crecimiento de las importaciones se explica por la estructura fabril heredada, que caracterizan como "desarticulada y trunca, muy sesgada hacia las primeras etapas de la transformación manufacturera y con marcadas heterogeneidades estructurales y desacoples en los niveles intra e interindustriales".

Ahora bien, tras la devaluación de 2002 se inicia un período expansivo caracterizado por infrecuente duración e intensidad, pues la serie de datos continuos sobre la actividad industrial disponibles desde 1970- muestran que nunca antes, desde el inicio de dicha serie, se habían verificado 24 trimestres consecutivos de crecimiento manufacturero, como los que se dieron desde el tercer trimestre de 2002 hasta el segundo trimestre de 2008 inclusive. Esos seis años de crecimiento manufacturero se desarrollaron a una tasa media acumulativa superior al 10,5\% anual, un ritmo inusualmente alto que caracterizó a este período (Herrera y Tavosnanska, 2011).

\section{Gráfico N²1. Producción industrial per cápita 1970-2008 (Índice 1970=100)}

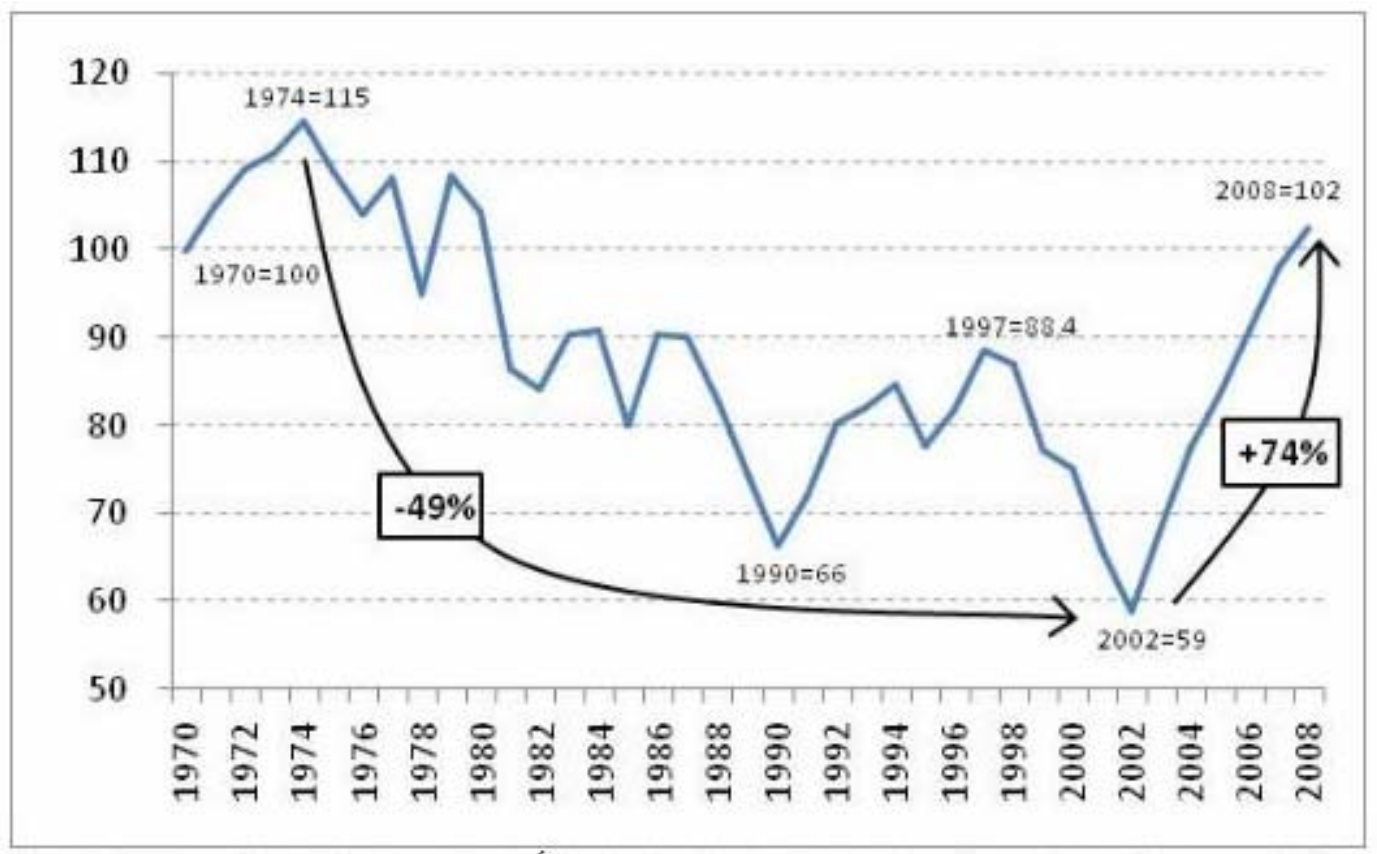

Fuente: Extraído de Herrera, G. y Tavosnanska, A. (2011) "¿Reindustrialización en la Argentina? Una década de expansión industrial en la Argentina". En: http://www.centrocultural.coop/revista/articulo/278/.

El gráfico $\mathrm{N}^{\circ} 1$ muestra claramente el punto crítico en cuanto a la producción industrial per cápita para el año 2002, para dar inicio, durante los años 2003 y 2004 a una etapa de recuperación, donde los niveles de crecimiento, según el INDEC cercanos al $16 \%$ anual, han mostrado un claro efecto "rebote" respecto de la fuerte caída previa, donde las empresas industriales responden al repunte vigoroso de la demanda a partir de la progresiva utilización de una capacidad instalada ociosa que había llegado a tocar un piso cercano al $56 \%$ en 2002. A continuación, se despliega una segunda fase de estabilización del crecimiento industrial -que se extiende entre 2005 y $2008-a$ una tasa media del 8,9\%. Durante esta segunda etapa el aumento de la producción se vio acompañado por nuevas inversiones; durante 2005 y 2006, cerca del $75 \%$ de la expansión productiva se vincula al crecimiento de la capacidad instalada, mientras que en 2007 y 2008 esto ya ocurre con prácticamente la totalidad del incremento productivo (Schvarzer et al, 2008). En este período también han jugado un

Publicado en formato digital: Mgter. Prof. Fernando Ariel Bonfanti. ANÁLISIS DEL MODELO DE INDUSTRIALIZACIÓN POR SUSTITUCIÓN DE IMPORTACIONES EN AMÉRICA LATINA Y EN ARGENTINA. UNA MIRADA HACIA LA REALIDAD INDUSTRIAL ACTUAL EN ARGENTINA. Revista Geográfica Digital. IGUNNE. Facultad de Humanidades. UNNE. Año 12. No 24. Julio - Diciembre 2015. ISSN 1668-5180 Resistencia, Chaco.

En: http://hum.unne.edu.ar/revistas/geoweb/default.htm 
rol importante las importaciones industriales (tanto de productos intermedios como finales) ya que comienzan a ganar participación progresiva en el consumo aparente de este segmento de bienes.

\section{El impacto de la crisis financiera internacional y la recuperación}

La industria argentina comenzó a disminuir sus niveles de producción hacia finales del año 2008, momentos en que comienzan a sentirse los cimbronazos de la crisis financiera internacional, que produjo la abrupta caída del comercio exterior (tanto en precios como en cantidades), y que en nuestro país tuvo su efecto multiplicador sobre el mercado local. Esta situación, definitivamente le puso un paréntesis al crecimiento de la industria argentina, afectando al consumo de bienes durables (disminuyó el consumo privado ante la pérdida de ingresos) y a la inversión (fundamentalmente por la creciente incertidumbre). Aunque, debe aclararse también que, al producirse la contracción del mercado interno, la mayoría de los sectores productivos afrontaron reducciones en la producción.

Según Herrera y Tavosnanska, para el año 2009 las exportaciones de manufacturas de origen agropecuario se redujeron un $11 \%$, mientras las manufacturas de origen industrial lo hicieron en un $15 \%$. Por otro lado, el empleo industrial cayó un 2,5 \% -según expresan estos autores-, dejando sin empleo a alrededor de 45 mil trabajadores registrados.

La crisis internacional, devenida en recesión local, llevó al gobierno a adoptar una serie de medidas para revertir sus efectos socioeconómicos. A diferencia de las experiencias previas, se articuló una política macroeconómica contracíclica, utilizando la demanda estatal para contrarrestar la caída del gasto privado, al mismo tiempo que se avanzaba en la protección del mercado interno. Las medidas de mayor impacto fueron el incremento de la inversión pública y la asignación universal por hijo, que impactaron de lleno en la actividad de la construcción y en el consumo de bienes de primera necesidad como alimentos e indumentaria, entre otros (Herrera y Tavosnanska, 2011).

Otra medida adoptada por el gobierno ha sido la extensión del Programa de Recuperación Productiva, mediante el cual se otorgaba subsidios a numerosas empresas con el fin de reducir las pérdidas de rentabilidad generadas por la crisis y evitar despidos masivos; asimismo también volvió a reflotarse el régimen de promoción fiscal a la producción nacional de bienes de capital; en este sentido, el sector electrónico en la provincia de Tierra de Fuego fue uno de los de mayor recuperación.

Por último, cabe una mención particular a la política de administración del comercio exterior y su extensión en este período. La aplicación de licencias no automáticas de importación y derechos antidumping fueron dos herramientas utilizadas por el gobierno para intervenir sobre los flujos de comercio exterior, promoviendo la fabricación local de productos industriales. Hasta el estallido de la crisis, esta política había estado concentrada fundamentalmente en una serie de sectores considerados "sensibles" (cuero, calzado, indumentaria, juguetes, etc.) por su fuerte capacidad de creación de puestos de trabajo y su fragilidad ante la competencia externa. Luego, en el contexto de fuerte caída de la demanda mundial, esta política se extendió (principalmente las licencias no automáticas de importación) para defender el empleo y el nivel de actividad ante la amenaza que existía por parte de ciertos países exportadores para que volcaran sus excedentes en el mercado local. A su vez, la caída de las exportaciones y la fuga de divisas redoblaron la necesidad de contener la entrada de bienes importados (Herrera y Tavosnanska, 2011). Al disminuir el nivel de las importaciones (desplazadas por producción local) se han generado mayores posibilidades para el ahorro de divisas.

A mediados del año 2009, la industria comenzó nuevamente a incrementar su nivel de producción de la mano de la recuperación del mercado local e internacional. En el plano externo, Sudamérica y Asia fueron las dos regiones que mejores respuestas articularon ante la crisis internacional, retomando rápidamente el crecimiento. Ello significó para nuestro país una pronta recuperación de su mercado de manufacturas industriales (especialmente Brasil) y agrarias (presencia creciente de Asia, sobre todo China). De esta manera, y de acuerdo a estadísticas del INDEC, en el año 2010 las MOA (Manufacturas de Origen Agropecuario) y las MOI (Manufacturas de Origen Industrial) crecieron un $7 \%$ y un $27 \%$ respectivamente, superando en el caso de las MOI los niveles máximos alcanzados dos años atrás. A nivel nacional, las políticas de demanda mencionadas

Publicado en formato digital: Mgter. Prof. Fernando Ariel Bonfanti. ANÁLISIS DEL MODELO DE INDUSTRIALIZACIÓN POR SUSTITUCIÓN DE IMPORTACIONES EN AMÉRICA LATINA Y EN ARGENTINA. UNA MIRADA HACIA LA REALIDAD INDUSTRIAL ACTUAL EN ARGENTINA. Revista Geográfica Digital. IGUNNE. Facultad de Humanidades. UNNE. Año 12. No 24. Julio - Diciembre 2015. ISSN 1668-5180 Resistencia, Chaco.

En: http://hum.unne.edu.ar/revistas/geoweb/default.htm 
anteriormente se conjugaron con la reactivación del empleo, la expansión de la cosecha (con precios nuevamente favorables), y la reactivación de la construcción.

La industria retomó así una velocidad de crecimiento similar a la que la caracterizó durante la etapa anterior a la crisis. Al interior del entramado manufacturero, las dinámicas de reacción fueron distintas: el sector automotriz, las industrias metálicas básicas, los bienes de capital y los insumos para la construcción se convirtieron en los de mayor crecimiento en el año 2010. En otras palabras, los segmentos de la industria que habían sido más afectados por la crisis internacional fueron luego los que pasaron a encabezar el crecimiento, al comenzar a recuperar (y luego superar) los niveles de producción máximos alcanzados previamente.

El incremento de la producción impulsó el alza del empleo, desandando de esta manera la caída previa. Hacia el primer trimestre del 2011 (según el INDEC) ya se habían recuperado prácticamente la totalidad de los puestos de trabajo perdidos en la crisis. El ritmo de absorción de nueva mano de obra se fue incrementando a medida que se consolidaba el crecimiento de la producción. Otro fenómeno que se produjo en este período ha sido el alza de la productividad, que se convirtió en un factor fundamental de la continuidad del proceso de expansión industrial.

En el Gráfico $N^{\circ} 2$ puede apreciarse la evolución histórica del coeficiente de industrialización (tamaño relativo de la industria) en la República Argentina desde 1875 hasta 2013, datos que han sido tomados de Orlando Ferreres y del Ministerio de Economía de la Nación.

\section{Gráfico № 2. Evolución de la industrialización argentina}

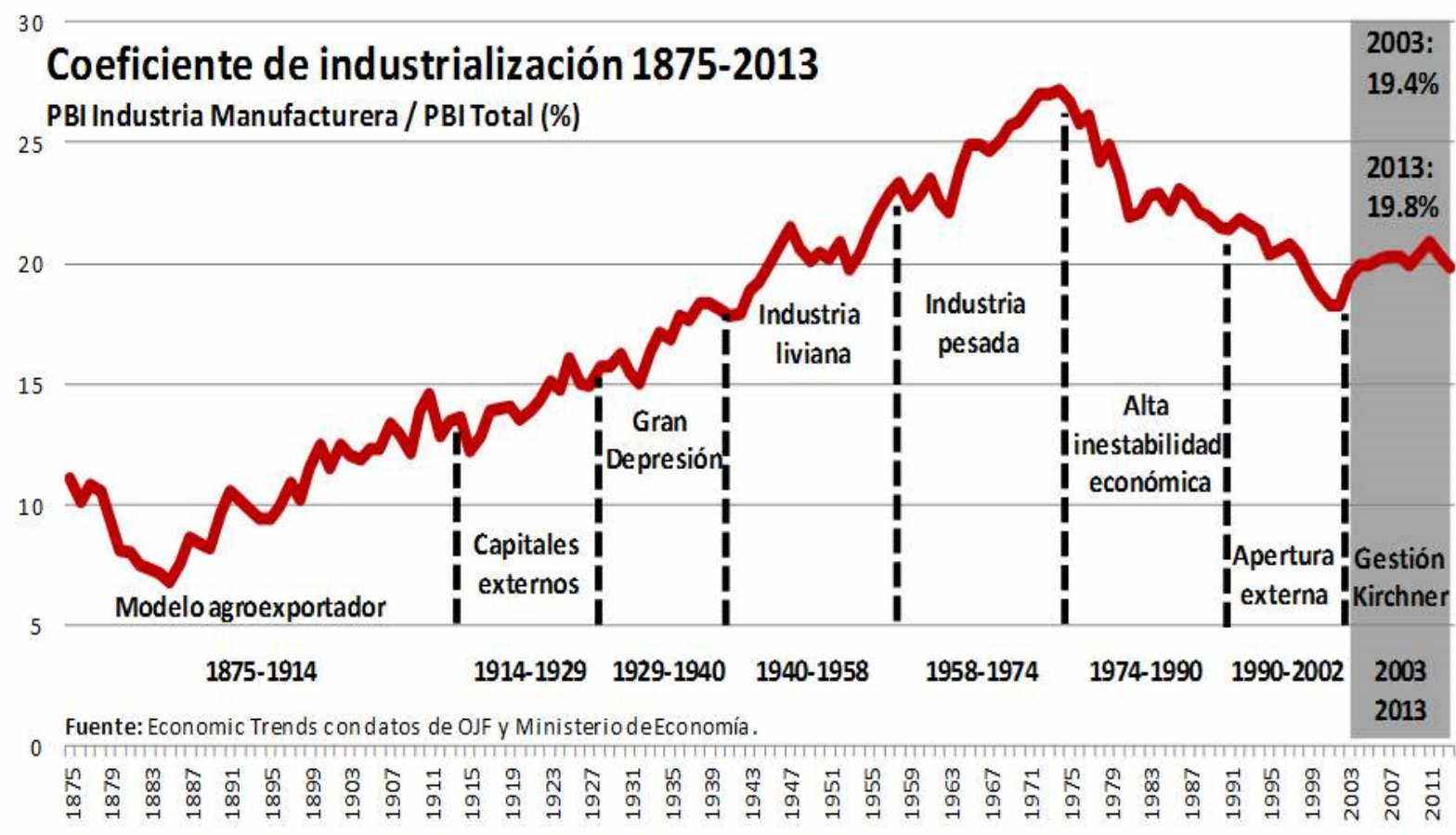

Fuente: Elaboración en base a estadísticas de “Dos Siglos de Economía Argentina 1875-1992 (Ferreres Orlando) y Ministerio de Economía de la Nación Argentina (1993-2013).

En el gráfico $\mathrm{N}^{\circ} 2$ se observan las distintas etapas que han caracterizado al desarrollo industrial argentino, desde el inicial modelo agroexportador de fines de siglo XIX, pasando por el período la llegada de capitales externos, la gran depresión de 1929-30 (que dejó sus respectivas secuelas en nuestro territorio), el desarrollo de las industrias liviana primero y pesada después hasta llegar a la situación de inestabilidad económica que caracterizó a gran parte del proceso de dictadura militar, la posterior apertura externa bajo el neoliberalismo y finalmente al modelo actual. A nivel

Publicado en formato digital: Mgter. Prof. Fernando Ariel Bonfanti. ANÁLISIS DEL MODELO DE INDUSTRIALIZACIÓN POR SUSTITUCIÓN DE IMPORTACIONES EN AMÉRICA LATINA Y EN ARGENTINA. UNA MIRADA HACIA LA REALIDAD INDUSTRIAL ACTUAL EN ARGENTINA. Revista Geográfica Digital. IGUNNE. Facultad de Humanidades. UNNE. Año 12. No 24. Julio - Diciembre 2015. ISSN 1668-5180 Resistencia, Chaco.

En: http://hum.unne.edu.ar/revistas/geoweb/default.htm 
general, se aprecia en la curva, una tendencia positiva entre 1885 (casi $8 \%$ del PBI) y 1974 (27\% del $\mathrm{PBI}$ ), una tendencia negativa desde entonces hasta 2003 (menos del $20 \%$ ), y un leve incremento hasta la actualidad. Uno de los factores más importantes que pueden explicar la pérdida del proceso de industrialización durante los últimos 40 años es la enorme inestabilidad que caracterizó a la economía argentina durante todos estos años.

En relación al intercambio comercial de Argentina desde 2004 a 2014 (gráfico №3) también se observa, pero a través de un gráfico de barras, el comportamiento manifestado en la curva del gráfico $\mathrm{N}^{\circ} 2$ (pero correspondiente a un período más corto).

\section{Gráfico Nº 3. Intercambio comercial argentino, período 2004-2014.}

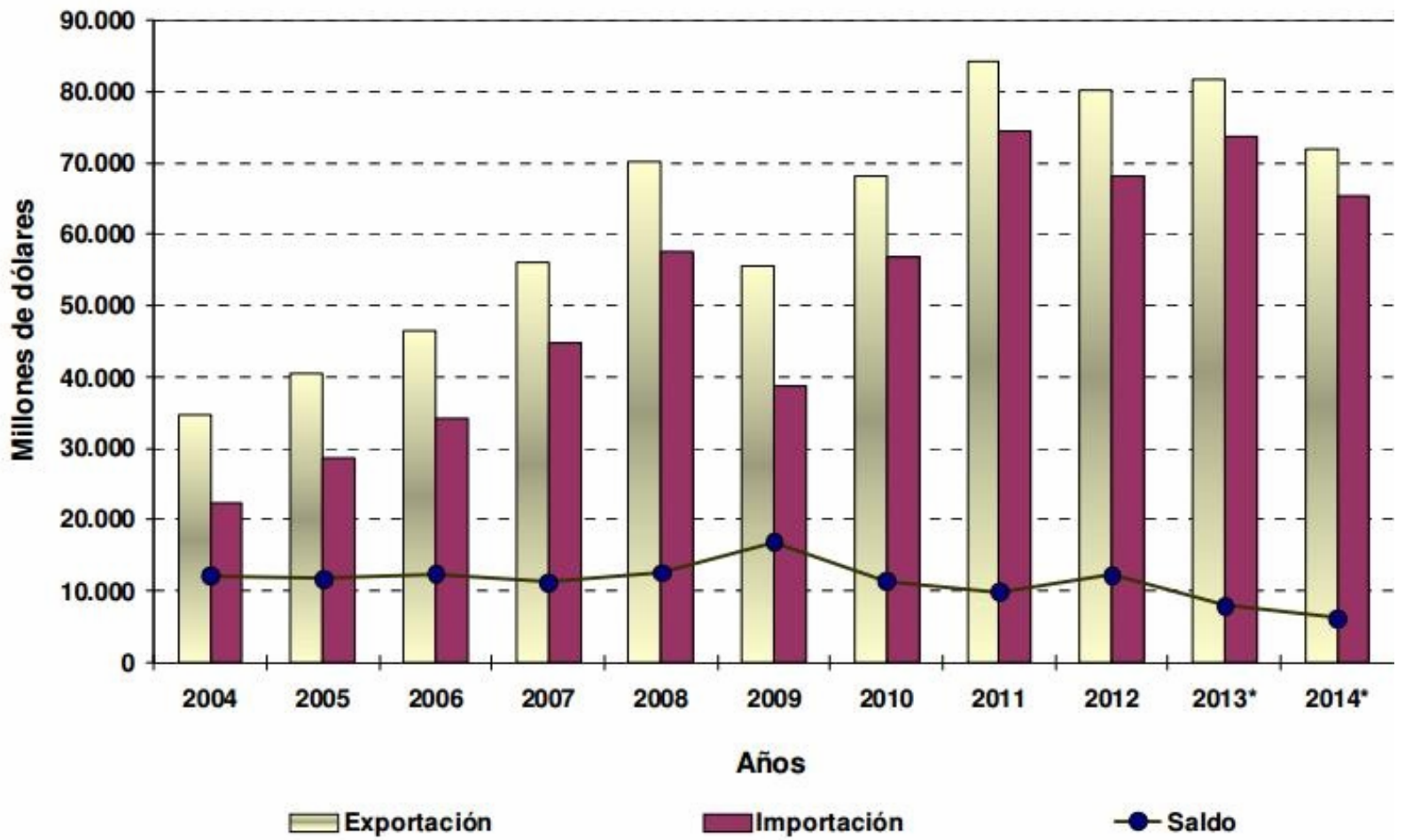

Fuente: Elaboración propia en base a estadísticas del Instituto Nacional de Estadística y Censos. Año 2014

En este gráfico se observa claramente que en el año 2014 la balanza comercial argentina arrojó un saldo positivo o superavitaria en un total de 6.686 millones de dólares, esto significó una caída del $17 \%$ con respecto al año anterior (según las estadísticas del INDEC). El total exportado fue de 71.935 millones contra 65.249 millones desembolsados en importaciones, con una variación negativa del $12 \%$ y del $11 \%$, respectivamente.

Los rubros de mayor participación en las exportaciones en 2014 fueron las Manufacturas de Origen Agropecuario y las Manufacturas de Origen Industrial, con el $39 \%$ y el $34 \%$ del valor total, respectivamente, según la fuente mencionada con anterioridad.

Sin lugar a dudas la producción que se genera a nivel nacional juega un rol fundamental para reducir el monto de las importaciones y lograr una balanza comercial superavitaria. El gráfico siguiente muestra que de haberse mantenido la misma participación de las importaciones en el PBI de 2008, la Argentina hubiera importado entre los años 2009 y 2014 más de 71.000 millones de dólares.

Publicado en formato digital: Mgter. Prof. Fernando Ariel Bonfanti. ANÁLISIS DEL MODELO DE INDUSTRIALIZACIÓN POR SUSTITUCIÓN DE IMPORTACIONES EN AMÉRICA LATINA Y EN ARGENTINA. UNA MIRADA HACIA LA REALIDAD INDUSTRIAL ACTUAL EN ARGENTINA. Revista Geográfica Digital. IGUNNE. Facultad de Humanidades. UNNE. Año 12. No 24. Julio - Diciembre 2015. ISSN 1668-5180 Resistencia, Chaco.

En: http://hum.unne.edu.ar/revistas/geoweb/default.htm 


\section{Gráfico $N^{\circ} 4$}

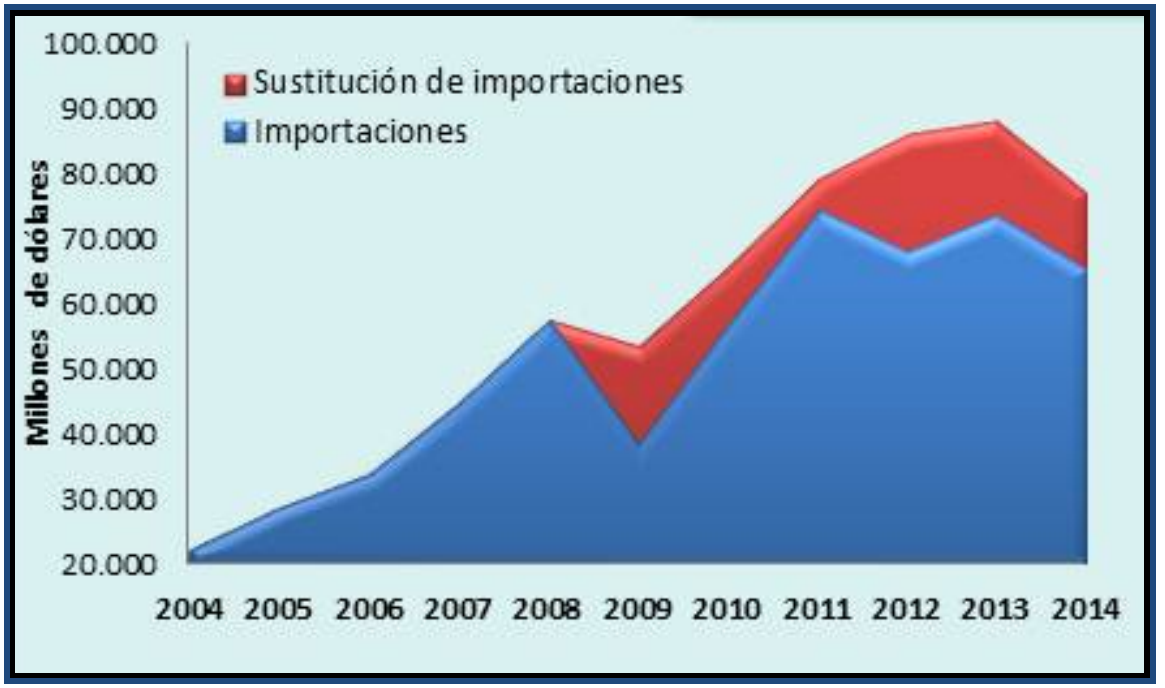

Fuente: Ministerio de Industria en base a INDEC

En este gráfico puede notarse claramente cómo las importaciones que han sido sustituidas en el período 2009-2014, por productos nacionales, ascendieron a 71.405 millones de dólares.

\section{Los Parques Industriales y la política de promoción industrial}

Un rasgo para destacar durante los últimos años es que el gobierno continuó con su política de federalizar la producción nacional a través de la creación de más Parques Industriales, que son predios especialmente diseñados para la radicación de industrias y servicios, respetando las particularidades regionales y localizados en armonía con los planes de desarrollo urbanos locales. Disponen de infraestructura y servicios comunes, favoreciendo el desarrollo de pequeñas y medianas empresas en el territorio nacional así como la generación de empleo genuino (Ministerio de Industria Argentina, 2013).

Constituyen un tipo de emprendimiento cuyo inicio se remonta a la década del '60, se expande en los '70 con los regímenes de promoción y vuelve a cobrar impulso tras las crisis de fines de 2001 y la finalización del período de convertibilidad.

Los beneficios a largo plazo que implica las instalación de parques industriales se encuentran íntimamente ligados a la capacidad de los municipios -allí donde se instalan- de desarrollar e implementar distintos tipos de herramientas de gestión, a su capacidad de negociación y a la voluntad política para la ejecutarlas (Tella y Robledo, 2011). Por lo tanto, un parque industrial no sólo constituye una concentración de empresas, también es un ámbito donde se produce una articulación y una asociación estratégica con impacto regional, una sinergia lograda a partir de la creación de un ámbito en común que permite trabajar mejor, aprovechar más los recursos y aportar valor a los productos nacionales.

Según el Ministerio de Industria de la Nación Argentina, la cantidad de parques industriales registrados actualmente en el RENPI (Registro Nacional de Parques Industriales) asciende a un total de 193, siendo la provincia de Buenos Aires la que cuenta con la mayor cantidad de ellos: 65 en total, según puede observarse en el gráfico $\mathrm{N}^{\circ} 5$. Cabe aclarar que los parques registrados son aquellos de carácter público u oficiales (originados por iniciativas de gobiernos provinciales y/o municipales), porque si a éstos se le adicionan los parques industriales privados (originados por iniciativas particulares, incluyendo cooperativas), los mixtos (originados a partir de iniciativas entre sectores públicos y privados) y los planificados alcanzan un total de 371 distribuidos por todo el territorio

Publicado en formato digital: Mgter. Prof. Fernando Ariel Bonfanti. ANÁLISIS DEL MODELO DE INDUSTRIALIZACIÓN POR SUSTITUCIÓN DE IMPORTACIONES EN AMÉRICA LATINA Y EN ARGENTINA. UNA MIRADA HACIA LA REALIDAD INDUSTRIAL ACTUAL EN ARGENTINA. Revista Geográfica Digital. IGUNNE. Facultad de Humanidades. UNNE. Año 12. No 24. Julio - Diciembre 2015. ISSN 1668-5180 Resistencia, Chaco.

En: http://hum.unne.edu.ar/revistas/geoweb/default.htm 
nacional, lo cual significa que hay cada vez más empresas aprovechando mejor los recursos para aumentar la productividad y competitividad, agregando valor y generando puestos de trabajo.

Esto se aprecia en las estadísticas del Ministerio de Industria del año 2015, que afirma que actualmente los 371 parques industriales ocupan una superficie de 20.850 hectáreas, albergando a un total de 4.936 empresas que generan 118.400 empleos. Esto es posible gracias al apoyo del Estado nacional, que a través del Programa Nacional para el Desarrollo de Parques Industriales Públicos en el Bicentenario (creado por decreto $N^{\circ} 915 / 2010$ ) bajo la órbita del Ministerio de Industria, contribuye al desarrollo de los Parques y de las empresas radicadas en ellos.

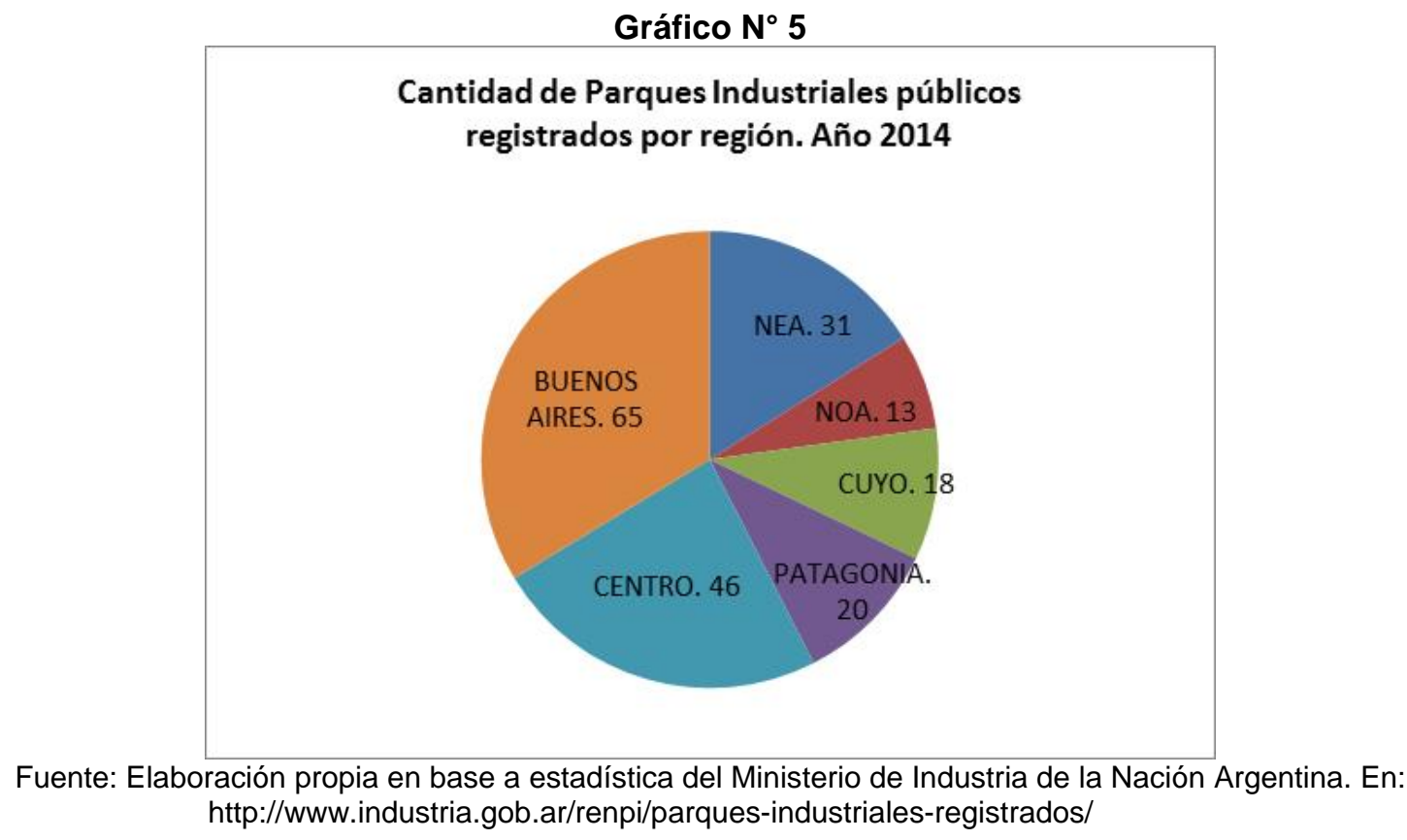

En los parques industriales no sólo hay Pymes (que trabajan con productos textiles, alimentos y bebidas, arquitectura y diseño, etc) sino que también se les da cabida a grandes empresas, en especial del sector agroalimentario, de electrodomésticos, metalmecánicas, de bio y nanotecnología, entre otras, cuyas producciones son hoy decisivas en la economía argentina.

La provincia de Buenos Aires es sin lugar a dudas la que mayor oferta de suelo industrial tiene, luego le siguen Santa Fe, Córdoba, Entre Ríos y Mendoza. Algunas particularidades para comentar son que la provincia de Catamarca fue una de las primeras en recibir promoción industrial durante la década del '70, mientras que el caso de Tierra de Fuego, que cuenta con Parques Industriales en Río Grande y Ushuaia, ocupa una pequeña superficie pero representan un modelo en cuanto a la generación de puestos de trabajo mayormente ligados a la industria electrónica, aunque también se destacan empresas del rubro textil, entre otras. Esto se debe a que en el año 2009 se crearon en esa provincia las condiciones necesarias para un fuerte proceso inversor que permitió el aumento de la producción con agregado de valor y el incremento del empleo, fundamentado en las estadísticas, que revelan que en la provincia de Tierra del Fuego existían en el año 2003 un total de 2.476 personas ocupadas en empresas beneficiadas por el régimen, mientras que en el 2012 ese número ascendió a 15.300 empleos (Galizia, 2014).

A modo de síntesis, y en relación a lo que el economista alemán Albert Hirschman llamó "la industrialización doblemente tardía" en las naciones latinoamericanas -para diferenciar los procesos de industrialización tardía de algunos países de Europa y Asia en la segunda mitad del siglo XX- el vertiginoso crecimiento industrial de la Argentina en apenas nueve años resulta digno de destacar, ya que el sector fabril se expandió durante el período 2003-2010 a un promedio anual de 9,5\%,

Publicado en formato digital: Mgter. Prof. Fernando Ariel Bonfanti. ANÁLISIS DEL MODELO DE INDUSTRIALIZACIÓN POR SUSTITUCIÓN DE IMPORTACIONES EN AMÉRICA LATINA Y EN ARGENTINA. UNA MIRADA HACIA LA REALIDAD INDUSTRIAL ACTUAL EN ARGENTINA. Revista Geográfica Digital. IGUNNE. Facultad de Humanidades. UNNE. Año 12. No 24. Julio - Diciembre 2015. ISSN 1668-5180 Resistencia, Chaco.

En: http://hum.unne.edu.ar/revistas/geoweb/default.htm 
ubicándose incluso dos puntos porcentuales por encima del crecimiento del PBI. Sólo en el último período se ha producido un leve retroceso, que incluso es menor al de nuestro principal socio comercial que es Brasil, según puede apreciarse en el gráfico que sigue a continuación.

\section{Gráfico $N^{\circ} 6$}

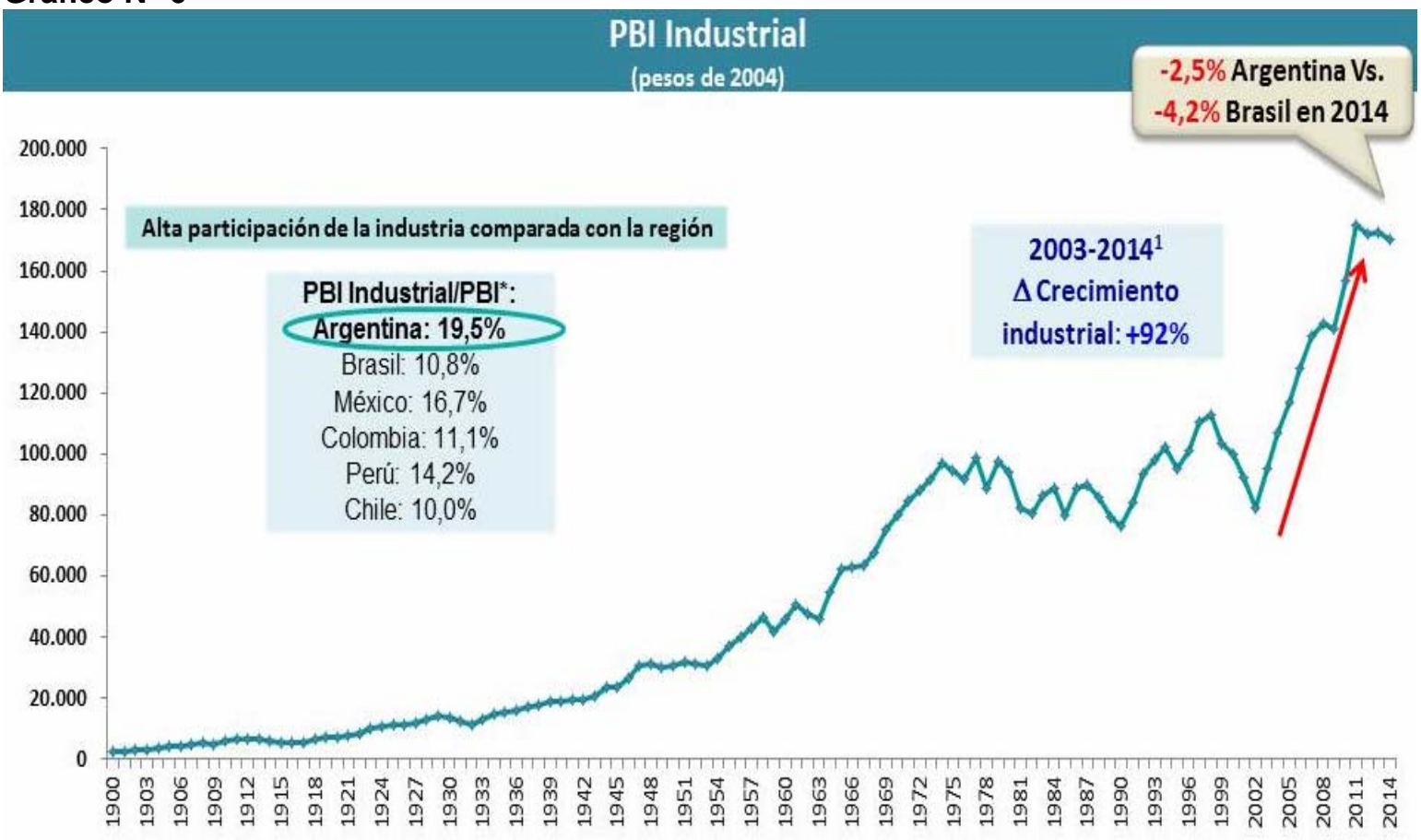

Fuente: Ministerio de Industria de la República Argentina. Institutos Estadísticos Nacionales de cada país referenciado

1- $\quad$ Corresponde a la Variación del EMI incluyendo el crecimiento del 2003. Cabe aclarar que el EMI es el Estimador Mensual Industrial, mide el desempeño del sector manufacturero sobre la base de información proporcionada por empresas líderes, cámaras empresarias y organismos públicos que informan sobre productos e insumos representativos.

\section{Consideraciones finales}

Desde principios de la década de 1950 hasta la década de los '80, la aplicación de las políticas industriales en los países de América Latina siguió la propuesta del modelo de sustitución de importaciones, la cual postulaba la intervención directa e indirecta del gobierno a través de incentivos fiscales, crediticios y protección comercial como mecanismo indispensable para lograr el desarrollo industrial nacional -que se justificaba por las debilidades estructurales de estas economías- ante la competencia internacional. La aplicación de este modelo de sustitución permitió a muchos países latinoamericanos entrar en un proceso de industrialización que duró alrededor de tres décadas.

A partir de mediados de los '80, todos los países de la región comenzaron de a poco a abandonar este modelo, situación que se produce en el marco de amplios procesos de reformas macroeconómicas y de apertura comercial, que implicaron, entre otras cuestiones, la eliminación o reducción de aranceles y subsidios y la privatización de empresas públicas para comenzar a atender a las nuevas exigencias de la competencia del mercado internacional, que incluía actividades con mayor dinamismo que permitan convertirse en los nuevos motores de la economía, rol que en algún momento jugaron las ramas alimenticias, textil, metalúrgica y automotriz.

Publicado en formato digital: Mgter. Prof. Fernando Ariel Bonfanti. ANÁLISIS DEL MODELO DE INDUSTRIALIZACIÓN POR SUSTITUCIÓN DE IMPORTACIONES EN AMÉRICA LATINA Y EN ARGENTINA. UNA MIRADA HACIA LA REALIDAD INDUSTRIAL ACTUAL EN ARGENTINA. Revista Geográfica Digital. IGUNNE. Facultad de Humanidades. UNNE. Año 12. No 24. Julio - Diciembre 2015. ISSN 1668-5180 Resistencia, Chaco.

En: http://hum.unne.edu.ar/revistas/geoweb/default.htm 
Así es como se inaugura una nueva etapa en la historia económica no sólo de Argentina sino de la mayoría de los países de Latinoamérica denominada "etapa neoclásica o liberal", caracterizada por una necesaria participación del Estado, que intentó eliminar los vicios, aunque las políticas utilizadas para lograrlo implicaron un cambio del escenario local y nuevas reglas del juego, para las que la industria local no estaba muy preparada.

Para nuestro país fue significativo lo que sucedió en la etapa posterior a las privatizaciones de empresas públicas, donde el Estado comenzó a idear una Política Industrial Nacional para federalizar la industria a través del apoyo a la creación de más parques industriales en todo el territorio nacional, apuntando a que las pymes instaladas en estos predios jerarquicen su producción, reduzcan costos en logística, agreguen valor en origen y aumenten su competitividad. Hasta el 2003 había sólo 80 parques industriales, pero desde esa fecha hasta la actualidad se han incrementado hasta llegar a 371 en todo el territorio nacional, lo cual ha representado la creación de más puestos de trabajo, el funcionamiento de casi 4.000 nuevas empresas y la ocupación de cerca de 20.000 hectáreas que en épocas pasadas estaban sin ocupar o abandonadas y que hoy están destinadas al uso industrial. Esto se da así aunque las pequeñas empresas efectivamente son más flexibles al cambio, varios aspectos de su estructura las hacen más vulnerables a las fluctuaciones económicas y a la extensión en el tiempo de una caída de la rentabilidad.

Con todo esto puede decirse entonces que luego de la salida de la Convertibilidad, la industria se ha convertido en uno de los motores del crecimiento agregado de la economía, esto se dio así porque el establecimiento de un tipo de cambio diferenciado mediante retenciones ha posibilitado su mayor incidencia en el PBI frente a una coyuntura internacional de persistente elevada cotización en los precios de las materias primas, que tensiona en sentido contrario a la industrialización. Lo propio puede decirse de la incidencia de la industria en el comercio exterior, con una participación de las manufacturas de origen industrial en el saldo total exportable cercano al 35 $\%$, hecho sin precedentes en la historia económica argentina reciente.

Con anterioridad a esa etapa, la producción industrial en nuestro país había sufrido drásticamente los efectos de la crisis 2001-02, período en el que se desaceleró, mostrando luego del período 2003-04 una etapa de recuperación y crecimiento y estabilización industrial que se extendió hasta 2008, con importantes incrementos en el sector productivo y acompañado por nuevas inversiones. Este leve crecimiento industrial se vio afectado por la crisis internacional de fines de 2009, que reflejó una caída en el sector, aunque es importante destacar que el retroceso solo fue temporal, ya que posterior a esa crisis, la actividad industrial mostró un claro crecimiento, fue recuperándose de a poco e incluso incrementó su producción y mantuvo niveles récords de producción desde 2011 hasta 2013, posicionándose como uno de los líderes de América del Sur, dejando atrás a Brasil e inclusive a México, sosteniéndose todo esto también con una política de gobierno que permitió generar más puestos de trabajo y liderando el proceso de cambio estructural en la región.

Este crecimiento fue impulsado especialmente por el desempeño del sector automotriz, que registró de enero a junio de 2013 un incremento de la producción del 19,8 \%, cerrando el mejor semestre del ciclo histórico, con el logro de una industria automotriz sustentable, con agregación de valor, tecnología e incremento de integración de partes nacionales. Sin embargo, el año 2014 no ha sido bueno, puesto que la producción de este segmento de empresas se derrumbó 5,5 \%.

En síntesis, la actividad industrial argentina cayó un 2,3 \% durante el año 2014, comportamiento que se explica por la retracción del sector automotriz, que se vio afectado por el menor crecimiento de nuestros socios comerciales brasileros.

Dada la alta incidencia que tiene el sector automotriz en el estimador de actividad industrial, el mal desempeño del mismo explica en gran parte la caída de la industria durante el 2014. El comportamiento del sector automotor responde a su alto grado de vulnerabilidad respecto al crecimiento de nuestros socios comerciales. El estancamiento de Brasil (que hace dos años que no crece) y la desaceleración de la economía mundial impactan de lleno en el sector.

Esta situación lleva a que en el último año y medio, la creación de empleo industrial se haya estancado aunque se han mantenido la cantidad de trabajadores en valores superiores a los 600.000,

Publicado en formato digital: Mgter. Prof. Fernando Ariel Bonfanti. ANÁLISIS DEL MODELO DE INDUSTRIALIZACIÓN POR SUSTITUCIÓN DE IMPORTACIONES EN AMÉRICA LATINA Y EN ARGENTINA. UNA MIRADA HACIA LA REALIDAD INDUSTRIAL ACTUAL EN ARGENTINA. Revista Geográfica Digital. IGUNNE. Facultad de Humanidades. UNNE. Año 12. No 24. Julio - Diciembre 2015. ISSN 1668-5180 Resistencia, Chaco.

En: http://hum.unne.edu.ar/revistas/geoweb/default.htm 
registrándose también un fuerte descenso del financiamiento, producto de la baja en el nivel de actividad y del encarecimiento del crédito.

\section{BIBLIOGRAFÍA}

- AZPIAZU, Daniel y SCHORR, Martín. (2010) "La industria argentina en la postconvertibilidad: reactivación y legados del neoliberalismo". Problemas de Desarrollo № 161, Vol. 41, México, 2010

- Centro de Estudios para la Producción (CEP). Ministerio de Industria de la Nación Argentina. En: http://www.industria.gob.ar/cep/informes-y-estadisticas/industriales/

- FAJNZYLBER, Fernando (1983) "La industrialización trunca de América Latina", Capítulo 5: "Reflexiones para una nueva industrialización", Editorial Nueva Imagen, Méjico. p. 346.

- FERRER, Aldo (2010) "La Nueva economía Argentina". Ensayo. Extraído de http://www.econ.uba.ar/planfenix/aportes/8/Ferrer/10/Ferrer\%20BAE\%20La\%20nueva\%20ec onom\%EDa\%20argentina.doc.

- FERRER, Aldo (2012) "La construcción del Estado Neoliberal en la Argentina". Artículo publicado en Revista de Trabajo. Año 8, Número 10 "Dinámica del trabajo en el marco de la incertidumbre global, pp. 99-108. Julio / Diciembre 2012. Ministerio de Trabajo, Empleo y Seguridad Social, Buenos Aires.

- FERRERES Orlando (2010) "Dos siglos de Economía Argentina 1810-2010". Edición Bicentenario. Editorial El Ateneo.

- GALIZIA, Francisco (2014) "Con parques industriales, se federaliza la producción". Artículo publicado en: http://www.ambito.com/diario/noticia.asp?id=758759

- GERALD, Valpy Fitz (1998) "La CEPAL y la teoría de la industrialización". Revista de la CEPAL número extraordinario. Tomado del sitio Web http://www.eclac.org/, 12-12-2007.

- GONZÁLEZ ARÉVALO, Ana Luisa "El proceso de sustitución de importaciones en América Latina. El caso México: 1940-1980". En: http://www.eumed.net/libros/2009a/513/Sustitucion\%20de\%20importaciones.htm

- GRUNWALD, J. (1964), "Invisible hands in inflation and growth" in BAER, W. AND KERSTENETZKY, I. (eds.), Inflation and Growth in Latin America, Amsterdam, Homewood.

- GUILLÉN, Arturo (2008) "Modelos de desarrollo y estrategias alternativas en América Latina". Tomado del sitio Web http://www.agapea.com/america-latina-y-desarrollo-economiconi390066i.htm, 24-01-2008.

- HERRERA, Germán; TAVOSNANSKA, Andrés. "¿Reindustrialización en la Argentina? Una década de expansión industrial en la Argentina". La revista del CCC [en línea]. Septiembre I Diciembre 2011, $\mathrm{n}^{\circ} 13 . \quad$ Disponible en Internet: http://www.centrocultural.coop/revista/articulo/278/. ISSN 1851-3263.

- HIRSCHMAN, Albert. O. (1996). "La economía política de la Industrialización por Sustitución de Importaciones". El trimestre económico, Vol. LXIII, 2, núm. 250, MX, México. pp. 180-192.

- LUSTIG, Nora (2000) "La CEPAL y el Pensamiento Estructuralista". Revista CEPAL en sus 50 años, Notas para un seminario conmemorativo, Chile.

- MINISTERIO DE INDUSTRIA (2013). Presidencia de la Nación. República Argentina. En: http://www.industria.gob.ar/parques-industriales-3/

- MUNS, J. (1972), “Industrialización y crecimiento de los países en desarrollo". Barcelona, Ed. Ariel.

- RODRÍGUEZ USE Jerónimo y WEIGANDI Iván (2015) "Informe de Coyuntura Económica N 5, Marzo 2015. Observatorio de Políticas Públicas. "Módulo de Políticas Económicas". Universidad Nacional de Avellaneda.

Publicado en formato digital: Mgter. Prof. Fernando Ariel Bonfanti. ANÁLISIS DEL MODELO DE INDUSTRIALIZACIÓN POR SUSTITUCIÓN DE IMPORTACIONES EN AMÉRICA LATINA Y EN ARGENTINA. UNA MIRADA HACIA LA REALIDAD INDUSTRIAL ACTUAL EN ARGENTINA. Revista Geográfica Digital. IGUNNE. Facultad de Humanidades. UNNE. Año 12. No 24. Julio - Diciembre 2015. ISSN 1668-5180 Resistencia, Chaco.

En: http://hum.unne.edu.ar/revistas/geoweb/default.htm 
- SONNTAG, Heinz. (1994) "Las vicisitudes del desarrollo". Revista internacional Ciencias Sociales, Julio 1994, p. 271.

- SCHVARZER, Jorge; D'ONGHIA, Maximiliano; ORAZI, Pablo y TAVOSNANSKA, Andrés (2008) "La actividad productiva en 2007. Un crecimiento que se consolida en distintos ámbitos". Notas de Coyuntura $\mathrm{N}^{\circ} 24$, Centro de Estudios de la Situación y Perspectivas de la Argentina, FCE UBA. Buenos Aires.

- TELLA, Guillermo y ROBLEDO, Laila. (2011), "Gestionar áreas industriales: Estrategias para el desarrollo económico local". En: Buenos Aires, Revista Mercado y Empresas para Servicios Públicos N 64 (octubre), Ed. IC Argentina.

- VACCAREZZA, Federico "Políticas de Desarrollo Industrial en la Argentina (1940-2001). Desde la sustitución a la apertura. Centro Argentino de estudios Internacionales. Extraído de: http://www.caei.com.ar/sites/default/files/ebook54.pdf

- VIDAL, Gregorio y GUILLÉN, Arturo (coordinadores) "Repensar la teoría del desarrollo en un contexto de globalización". Enero, 2007, tomado del sitio Web www.clacso.org.ar/biblioteca.edu.ar, 5-10-2007.

Publicado en formato digital: Mgter. Prof. Fernando Ariel Bonfanti. ANÁLISIS DEL MODELO DE INDUSTRIALIZACIÓN POR SUSTITUCIÓN DE IMPORTACIONES EN AMÉRICA LATINA Y EN ARGENTINA. UNA MIRADA HACIA LA REALIDAD INDUSTRIAL ACTUAL EN ARGENTINA. Revista Geográfica Digital. IGUNNE. Facultad de Humanidades. UNNE. Año 12. No 24. Julio - Diciembre 2015. ISSN 1668-5180 Resistencia, Chaco.

En: http://hum.unne.edu.ar/revistas/geoweb/default.htm 